\title{
"O MARCO DE 1989": UMA REFLEXÃO SOBRE OS XVIII JOGOS ESCOLARES BRASILEIROS
}

\author{
"THE 1989 LANDMARK": A REFLECTION ON THE $18^{\text {th }}$ BRAZILIAN SCHOOL \\ GAMES
}

"EL HITO DE 1989": UNA REFLEXIÓN SOBRE LOS XVIII JUEGOS ESCOLARES BRASILEÑOS

\author{
Taiza Daniela Seron Kiouranis ${ }^{*}$, Leila Salvini ${ }^{*}$ Wanderley Marchi Júnior
}

Palavras chave: Atletismo.

Sociologia.

Esportes.

Brasil.

Keywords:

Track and field.

Sociology.

Sports.

Brazil.

Palabras clave: Atletismo.

Sociología.

Deportes.

Brasil.
Resumo: O objetivo deste artigo é descrever as características dos JEBs de 1989 e identificar agentes e estratégias de ação para o desenvolvimento de um modelo para o esporte escolar. Utilizamos como fonte de informações uma entrevista e uma fonte literária. Tendo como referencial de análise a Teoria dos Campos de Pierre Bourdieu, foi possível concluir que os agentes que idealizaram a ação em questão eram oriundos (em sua maioria) do campo acadêmico, e numa tentativa pouco profícua tentaram inculcar 0 habitus desse campo em uma estrutura esportiva, vinculada às ações práticas alicerçadas na competição.

Abstract: The purpose of this article is to describe the characteristics of the 1989 Brazilian School Games and identify agents and strategies for the development of a model for school sports. Our source of information was an interview and a literature source. With the analytical framework of Pierre Bourdieu's theory of fields, we concluded that the agents who idealized the games came mostly from the academic field. Not very fruitfully, they tried to inculcate the habitus of that field in a sports structure linked to the practical actions rooted in the competition.

Resumen: El propósito de este artículo es describir las características de los JEBs de 1989 e identificar agentes y estrategias de acción para el desarrollo de un modelo para el deporte escolar. Se utilizó como fuente de información una entrevista y una fuente literaria. Teniendo como referencia de análisis la teoría de los campos de Pierre Bourdieu, se concluyó que los agentes que idealizaron esta acción procedían (en su mayoría) del ámbito académico, y en un intento poco fructífero trataron de inculcar el habitus de ese campo en una estructura deportiva, vinculada a las acciones prácticas basadas en la competición.
*Universidade Federal do Paraná. Curitiba, PR, Brasil. E-mail: taizaseron@ hotmail.com; leila.salvini@gmail.com; wmarchijr@gmail.com

Recebido em: 18-04-2016 Aprovado em: 01-02-2017

(c) (i) () Licence 


\section{INTRODUÇÃOO}

Em nosso país, a trajetória de competições escolares nacionais se iniciou ao final da década de 1960, com a realização dos I Jogos Estudantis Brasileiros. Surgidos em pleno auge do regime militar, esses eventos, até meados da década de 1980, foram conduzidos de modo a contribuir com o projeto político-ideológico da época. Após a abertura política brasileira em 1985, o campo político-esportivo sofreu mudanças significativas, que reverberaram também na forma de desenvolvimento dos Jogos. Dentre os acontecimentos marcantes desse período destacam-se a reconfiguração política e social e os movimentos nacionais e internacionais relacionados ao esporte. No âmbito nacional, o esporte foi assunto de discussões na área da Educação Física, sendo apontada a necessidade de uma reformulação de sua prática (MEDINA, 1987; LINHALES, 1996; TUBINO, 2010).

Tendo em vista esse contexto político e social, no ano de 1989, os Jogos Escolares Brasileiros ${ }^{1}$ (JEBs) foram realizados de forma totalmente atípica, apresentando-se como um fato único na história das competições escolares nacionais. 0 modelo rompeu com os padrões de competições escolares que vinham sendo adotados até o momento e seguiu os princípios educativos associados ao esporte educacional ${ }^{2}$. Constituíram-se como uma referência de mudança de sentido, ou seja, "uma manifestação inequívoca de ação educativa, em vez de apresentarem-se mais uma vez como reprodução do chamado Esporte de Rendimento" (BRASIL, 1989, p. 7).

A ediçãofoi considerada um "marco" na história dos Jogos e do esporte escolar brasileiros e carregou uma simbologia peculiar para a época, não obtendo êxito em sua continuidade. Sendo assim, pelo seu caráter extraordinário e pela sua forma distinta de desenvolvimento, encontramos possibilidades profícuas de reflexão ao analisarmos esse caso particular de forma sistemática. Para tanto, propomos como objetivo descrever as características dos JEBs de 1989 e identificar os agentes e as estratégias de ação para o desenvolvimento de um modelo para 0 esporte escolar. Nesse sentido organizamos o presente artigo apresentando inicialmente alguns elementos da Teoria dos Campos de Pierre Bourdieu, e em seguida, descrevemos o período de pré-constitucionalização do esporte no Brasil e a estrutura dos JEBs 1989.

\section{ASPECTOS METODOLÓGICOS}

De caráter exploratório, este estudo de caso utilizou como fontes de dados a entrevista e 0 documento (fonte literária). A pesquisa encontra respaldo no Certificado de Apresentação para Apreciação Ética (CAAE), nํ. 47607114.8.0000.0102, expedido pelo Comitê de Ética em Pesquisa da Universidade Federal do Paraná , tendo sido aprovado pelo parecer n.ำ 1.283.908, assegurando 0 desenvolvimento desta investigação segundo padrões éticos e preservando 0 sujeito envolvido.

A entrevista foi realizada com um consultor do Ministério do Esporte (ME), que denominaremos de "Agente/ME" ${ }^{3}$, e que possui experiência de pelo menos 30 anos como coordenador na área de esporte e lazer da extinta Secretaria de Educação Física e Desportos

1 A partir de 1976, os Jogos Estudantis Brasileiros passaram a ser denominados de Jogos Escolares Brasileiros.

2 De acordo com Brasil (1998, art. 3ํ, inciso I), o esporte educacional é aquele "praticado nos sistemas de ensino e em formas assistemáticas de educação, evitando-se a seletividade, a hipercompetitividade de seus praticantes, com a finalidade de alcançar o desenvolvimento integral 
do Ministério da Educação (SEED/MEC) e como coordenador de modalidades durante os Jogos de 1989. A entrevista foi realizada no ano de 2015 pelos próprios pesquisadores em local e horário previamente agendado com o entrevistado e seguiu o modelo semiestruturado. A entrevista foi transcrita na íntegra e sistematizada para análise levando em consideração somente fragmentos de maior pertinência à discussão proposta.

Como fonte suplementar para a análise, utilizamos a obra publicada em 1989 pela SEED/MEC, intitulada de "Esporte na escola: os XVIII Jogos Escolares Brasileiros como marco reflexivo". Dentre suas partes constituintes focamos nos itens: "1. Documentos que subsidiaram repensar o esporte na escola" e "2. A estrutura dos XVIII Jogos Escolares Brasileiros como meio efetivo de inovação e mudança" (BRASIL, 1989). A partir da fonte literária, apresentamos uma síntese do assunto central dos documentos que subsidiaram a formulação dos Jogos de 1989 e de sua estrutura organizacional. Como subsídio para a análise, exploramos alguns conceitos sociológicos de Pierre Bourdieu, especialmente a noção de campo, o qual emergiu nas análises dos dados, tornando-se um conceito relevante para a proposta apresentada.

\section{UM BREVE PANORAMA SOBRE O FUNCIONAMENTO DOS CAMPOS}

Antes de tecermos informações sobre a Teoria dos Campos elaborada pelo sociólogo francês Pierre Bourdieu, é importante que tenhamos em mente a visão relacional que o autor propõe aos seus conceitos, os quais somente adquirem significado dentro de um sistema de relações (BOURDIEU; WACQUANT, 2005). Nesse sentido, as noções de campo, habitus e capitais são indissociáveis, sendo apresentadas separadamente somente para fins didáticos.

Os campos se apresentam como espaços estruturados de posições que podem ser analisadas independentes das características de seus ocupantes, mas que são, em parte, determinados por eles. Bourdieu (2003) propõe que existem "leis gerais dos campos", ou seja, leis de funcionamento invariantes que tornam a Teoria dos Campos uma teoria geral, tendo em vista que o que se aprende sobre um campo em específico pode ser aplicado em outro distinto. Desse modo, uma análise primordial de qualquer campo passa pela identificação dos mecanismos genéricos de funcionamento, comum a todos os campos.

Um campo se define, entre outras coisas, através da determinação dos objetos de disputa, os quais juntamente com as pessoas prontas para disputar o jogo são fundamentais para que um campo funcione. A ideia de jogo proporciona uma primeira compreensão de campo, embora o autor ressalve que o campo não seja o produto de uma criação deliberada e suas regras nem sempre são explícitas ou codificadas (BOURDIEU; WACQUANT, 2005). Para que seja possível "jogar o jogo", é necessário que as pessoas sejam dotadas do habitus "[...] que implica o conhecimento e o reconhecimento das leis imanentes do jogo, das paradas em jogo, etc." (BOURDIEU, 2003, p. 120).

Essa lei relaciona-se ao que Bourdieu (1996, p. 140) denominou de illusio, que de acordo com ele significa essa relação, entre o agente e o campo, de "[...] estar envolvido, e investir nos alvos que existem em certo jogo, por efeito da concorrência, e que apenas existem para as pessoas que, presas ao jogo, e tendo as disposições para reconhecer os alvos que aí estão em jogo [...]". Esses agentes em disputa ocupam posições distintas, ou seja, os que são legítimos ou dominantes e os que são novos ou dominados, e podem através de seu embate produzir estratégias e ações práticas que mantenham (ortodoxia) as posições ou as corrompam 
(heterodoxia) (BOURDIEU, 2003). Sendo assim, a disputa em campo passa também por uma disputa da legitimidade do que está em jogo.

Seguindo nessa analogia, salientamos a existência de "cartas de triunfo", isto é, "cartas mestras cuja força cairia segundo o jogo, assim como o valor relativo das cartas muda para cada jogo, a hierarquia das diferentes espécies de capital (econômico, social, cultural, simbólico) varia nos diferentes campos" (BOURDIEU; WACQUANT, 2005, p. 151). Nesse sentido, o valor de uma espécie de capital depende da existência de um jogo, de um campo, onde tal competência possa ser utilizada.

E por último, não menos importante, trata-se da presença da doxa, ou de uma opinião consensual, um conjunto de interesses que perpetuam a existência do campo. Todas as pessoas, ou agentes empreendidos num campo "têm em comum um certo número de interesses fundamentais, a saber, tudo o que está ligado à própria existência do campo: daí uma cumplicidade objectiva que está subjacente a todos os antagonismos" (BOURDIEU, 2003, p. 121).

A partir do entendimento do funcionamento dos campos e da possibilidade de influências mútuas entre eles, é que propomos para este artigo um olhar sob o subcampo da Educação Física Escolar, mais precisamente, para a estrutura dos JEBs 1989, contemplado no esporte escolar, que no nosso entendimento e para o recorte aqui proposto, está interligado aos campos político-esportivo e acadêmico. Nesse contexto, como forma de apresentar o subcampo da Educação Física Escolar sob influência dos campos acima mencionados, trazemos uma descrição sobre o período de pré-constitucionalização do esporte no Brasil e posteriormente propomos uma análise sobre o que estamos chamando de "O marco de 1989": entre as potencialidades e a realidade.

\section{COMPONDO O CENÁRIO COM A IDENTIFICAÇÃO DOS AGENTES: O PERÍODO DE PRÉ-CONSTITUCIONALIZAÇÃO DO ESPORTE NO BRASIL}

A partir de meados da década de 1970, o Brasil iniciou um processo de transição democrática, que culminou no advento da Nova República em 1985, com a eleição do primeiro presidente civil após o regime militar e o seu governo "Tudo pelo Social". Houve na esfera política uma intensificação da democratização, marcada pelo estabelecimento de "condições livres de participação e contestação [...] e, acima de tudo, a refundação da estrutura constitucional brasileira com a promulgação de uma nova Constituição em 1988" (KINZO, 2001, p. 8).

No campo político-esportivo, até 1985, o esporte era normatizado pelo Decretolei $n^{\circ}$ 3.199/1941, pelas deliberações do Conselho Nacional de Desportos (CND), pela Lei 6.251/1975 e pelo Decreto $n^{\circ}$ 80.228/1977, documentos marcados pelo autoritarismo, e que produziam certa tutela e cartorialização do esporte (TUBINO, 2002). A partir de 1985, ações de mudança foram observadas nesse setor, especialmente pela emergência de debates sobre 0 esporte como direito social e o esporte educacional (TUBINO, 1996). Dentre elas destaca-se a instituição da "Comissão de Reformulação do Esporte", que realizou estudos sobre o esporte nacional, apresentando propostas a partir da consulta a especialistas, entidades e instituições relacionadas ao setor (MENDES, 1990; TUBINO, 2002). Essa ação foi um indício da necessidade da Educação Física e do esporte acompanharem o processo de redemocratização, tal como vinha acontecendo em outras áreas (BUENO, 2008). 
Dentre as propostas dessa comissão, destacamos a apresentação do esporte como um direito social, oferecido a partir de três manifestações básicas: esporte-educação, esporteparticipação e esporte performance, tendo como prioridade o esporte educacional na destinação dos recursos. Embora concordemos com Linhales (1996), ao afirmar que as manifestações apenas ganharam uma nova roupagem, consideramos que a mudança foi fruto de intensos debates na área, os quais não limitaram a Educação Física ao esporte e que foram motivados por movimentos e concepções diferentes de participação esportiva, tal como o movimento "Esporte para Todos". Assim, se na prática o modelo era o mesmo, é possível que no âmbito do debate vislumbrassem-se outras perspectivas de participação. Além disso, na leitura de Tubino (2005), ao ser estabelecida a necessidade de renovar o conceito de esporte, essa comissão contribuiu para que alcançasse o status de direito fundamental.

Vale frisar que, no campo político-esportivo internacional, discussões que se pautavam na integração da educação e do esporte vinham sendo realizadas desde a década de 1960, unindo educação e esporte "no discurso de formação humana integral na linha de defesa dos Estados e de organismos internacionais" (DANTAS JUNIOR, 2010, p. 152). Alguns "movimentos esportivos" que se sucederam nesse período merecem destaque, como o Movimento Esporte para Todos (EPT) que teve origem na Noruega com o nome de "TRIMM"; a inserção de sociólogos e cientistas políticos do esporte; e os manifestos de organizações internacionais: Manifesto do Esporte (1968), do Conseil International d'Éducation Physique et Sport (CIEPS); Manifesto Mundial da Educação Física (FIEP) (1970); Carta Europeia de Esporte para Todos (1975); Manifesto do Fair Play (1975), do Conseil International du Fair Play (CIFP); Carta de Paris (1976); e A Carta Internacional de Educação Física e Esporte da UNESCO (1978) (TUBINO, 1996; 2008; 2010; CAVALCANTE, 2010).

No campo acadêmico havia também sinais de um período transitório. Bueno (2008) destaca o surgimento de uma "crise de identidade", marcada por uma fase de intenso questionamento sobre o papel da Educação Física na sociedade e uma crítica acentuada ao esporte de rendimento, motivada pela influência das teorias críticas da educação e da sociologia crítica do esporte (BRACHT, 2000). Desse modo, percebe-se a partir da década de 1980, a formação de um grupo de intelectuais no contexto acadêmico da Educação Física brasileira que produziu um corpo teórico crítico que embasou seu posicionamento contra o modelo hegemônico de esporte que vinha sendo reproduzido, inclusive, no âmbito escolar (BRACHT, 1992, p. 22). Assim, o status quo do esporte brasileiro começou a sofrer certa instabilidade.

Alguns agentes protagonistas dessa nova tendência da Educação Física fizeram parte também das discussões sobre esporte educacional no campo político-esportivo. Segundo Barbieri (1999), o modelo dos Jogos de 1989 partiu de diversos debates liderados, a partir de 1985, por Manuel José Gomes Tubino e Bruno Silveira e que contaram com a participação direta ou indireta, dentre outros educadores, de Lino Castellani, João Batista Freire, Celi Taffarel, Person Cândido Matias da Silva, Laércio Elias Pereira, Florismar Oliveira Thomaz e Silvino Santin, com o objetivo de ressignificar o esporte no contexto educacional (BARBIERI, 1999). Vale ressaltar que tais gentes ocupavam posição de destaque no campo acadêmico e transitavam com certa legitimidade também nos campos político-esportivo e da educação. Por esse motivo, suas ideias e ações eram disseminadas.

Em nosso entendimento, as discussões travadas nesse período marcam até hoje a relação polêmica e muitas vezes controversa entre os Jogos e o esporte educacional. Esse 
fato tem gerado inúmeras contradições de interpretação entre os agentes que transitam pelo esporte escolar e pelo campo político-esportivo. Enquanto o primeiro critica as competições afirmando que se trata de um reflexo do alto rendimento, o segundo assume que as competições são legítimas e não prejudicam o andamento das ações esportivas na escola. 0 contexto apresenta uma disputa entre diferentes agentes pela legitimidade do esporte escolar, cada qual defendendo seus interesses e sua posição de dominante, utilizando seus capitais e acreditando que as ações práticas - leia-se habitus - oriundas de cada um dos campos eram "o mais legítimo" para ser incorporado às práticas esportivas na Educação Física Escolar.

\section{MARCO DE 1989 E SUA ESTRUTURA: ENTRE POTENCIALIDADE E A REALIDADE}

De 1985 a 1989, a SEED/MEC foi a principal organizadora ${ }^{4}$ e financiadora dos jogos escolares. Nesse período, os objetivos e finalidades desses eventos estavam pautados na visão educacional, buscando a desvinculação com competições que objetivavam, sobretudo, 0 rendimento esportivo (ARANTES; MARTINS; SARMENTO, 2012). A 18ª edição dos Jogos marcou 0 auge dessa nova fase (BORGES; BUONICORE, 2007). Após quase 15 anos de reprodução do modelo de esporte de alto rendimento, podemos afirmar que os jogos escolares foram submetidos a uma reflexão crítica e, de acordo com Pires e Silveira (2007), repensados e reconstruídos em diferentes perspectivas socioculturais. De acordo com Brasil (1989), foram sete referenciais que subsidiaram esse processo de mudança, os quais, sinteticamente, preconizavam:

Quadro 1 - Síntese dos assuntos centrais presentes nos documentos que subsidiaram a reformulação dos JEBS de 1989 a deflagração do processo de reconsideração do esporte na escola

\begin{tabular}{|c|c|c|}
\hline Documento & Responsável/Data & Assunto principal \\
\hline $\begin{array}{l}\text { 1) Indicação n } 2 \text { - } \\
\text { Título: do conceito } \\
\text { de esporte no Brasil }\end{array}$ & $\begin{array}{l}\text { Comissão de } \\
\text { Reformulação do } \\
\text { Desporto/Dez.1985 }\end{array}$ & $\begin{array}{l}\text { O esporte como atividade predominantemente física, de } \\
\text { caráter formativo-emocional, participativo e competitivo, e } \\
\text { na abrangência do Esporte-Educação, Esporte-participação, } \\
\text { Esporte-Performance. }\end{array}$ \\
\hline $\begin{array}{l}\text { 2) Indicação nº } \\
3 \text { - Título: da } \\
\text { manifestação } \\
\text { Esporte-educação }\end{array}$ & $\begin{array}{l}\text { Comissão de } \\
\text { Reformulação do } \\
\text { Desporto/ Dez.1985 }\end{array}$ & $\begin{array}{l}\text { O esporte-educação como manifestação desenvolvida } \\
\text { especialmente na escola (integrado aos programas de } \\
\text { Educação Física), visando à formação integral, devendo } \\
\text { ainda, favorecer o desenvolvimento diversificado, completo e } \\
\text { harmonioso do homem, podendo ser um meio de descoberta e } \\
\text { desenvolvimento para o esporte-performance, e ser prioridade } \\
\text { nos programas que atendam ao menor carente. }\end{array}$ \\
\hline $\begin{array}{l}\text { 3) Constituição } \\
\text { Brasileira de } 1988\end{array}$ & \begin{tabular}{|l} 
Brasil-Congresso \\
Constituinte/ Out.1988
\end{tabular} & Esporte como um direito de cada um e dever do Estado. \\
\hline $\begin{array}{l}\text { 4) Recomendação } \\
\text { CND NP nº. } 01\end{array}$ & $\begin{array}{l}\text { Conselho Nacional de } \\
\text { Desportos/Mai.1989 }\end{array}$ & $\begin{array}{l}\text { Conceito de esporte educacional e inclusão de dispositivos } \\
\text { na LDBEN: a) Educação Física indissociável da Educação } \\
\text { e obrigatória no ensino fundamental e médio; b) práticas } \\
\text { esportivas formais e não formais no ensino fundamental, médio } \\
\text { e superior; c) esporte educacional como prioridade dos recursos } \\
\text { do Ministério da Educação para desporto. }\end{array}$ \\
\hline $\begin{array}{l}\text { 5) A educação em } \\
\text { primeiro lugar }\end{array}$ & $\begin{array}{l}\text { Manoel José Gomes } \\
\text { Tubino/Jun.1989 }\end{array}$ & $\begin{array}{l}\text { Crítica aos JEBs desenvolvidos até aquele momento. } \\
\text { Descrição de como os princípios de Participação, Cooperação, } \\
\text { Coeducação, Cogestão/Corresponsabilidade e Integração } \\
\text { seriam efetivados na edição de 1989. Anunciação dos Jogos de } \\
1989 \text { como uma manifestação legítima de esporte educacional. }\end{array}$ \\
\hline
\end{tabular}

Continua na próxima página...

4 Até 1977 o principal organizador dos Jogos foi o Departamento de Educação Física e Desporto (DED/MEC). A partir de 1979 a Secretaria de Educação Física e Desportos (SEED/MEC) assume a organização desses eventos. Em 1978 não houve Jogos nacionais, apenas etapas estaduais. 
Continuação do quadro 1 ...

\begin{tabular}{|l|l|l|}
\hline $\begin{array}{l}\text { 6) Por uma carta } \\
\text { de princípios para o } \\
\text { esporte-educação } \\
\text { no Brasil }\end{array}$ & $\begin{array}{l}\text { Manoel José Gomes } \\
\text { Tubino/1989 }\end{array}$ & $\begin{array}{l}\text { Estabelecimento dos objetivos que subsidiam o conceito } \\
\text { de esporte-educação. Destaque ao papel do Estado e da } \\
\text { Sociedade no Esporte-Educação. Estabelecimento do papel } \\
\text { dos educadores diante do esporte-educação. Apresentação das } \\
\text { referências para as competições de esporte-educação no Brasil. }\end{array}$ \\
\hline $\begin{array}{l}\text { 7) JEBs, Esporte e } \\
\text { Educação }\end{array}$ & $\begin{array}{l}\text { Manoel José Gomes } \\
\text { Tubino/Jul.1989 }\end{array}$ & $\begin{array}{l}\text { Descrição do conceito de esporte até a década de } 1960 \text { (alto } \\
\text { rendimento) e como os Jogos seguiram essa tendência. Aborda } \\
\text { sobre o desafio de revolucionar esses eventos, afirmando o } \\
\text { sucesso da edição de 1989, inclusive como representante de um } \\
\text { marco do início da discussão de Esporte-Educação no Brasil. }\end{array}$ \\
\hline
\end{tabular}

Fonte: BRASIL (1989, p. 11-30).

Destaca-se, nos documentos 1 a 4, a formação de uma comissão de "agentes reformadores do esporte" no campo político-esportivo, os quais, pela potencialidade de seus capitais, definiram um novo conceito para o esporte brasileiro, inclusive com repercussões na Constituição Brasileira de 1988 e no campo da educação pelo estabelecimento de formas de sua abordagem na nova LDBEN através da manifestação de esporte educacional na escola. Vale destacar que, até aquele período, era o alto rendimento o modelo legítimo (ortodoxo) do esporte que se desenvolvia no contexto escolar.

Em um segundo momento, a partir dos documentos 5 a 7, percebemos a intenção dos agentes em adotar a nova concepção que propunham para o esporte brasileiro, a qual conferiria ao JEBs 1989 um status de "manifestação legítima de esporte educacional". Percebe-se ainda pela descrição dos documentos uma negação (disputa), por parte desses mesmos agentes, das ações práticas que vinham se desenvolvendo até aquele período no âmbito do esporte escolar, que envolvia tanto o campo político-esportivo como o campo acadêmico.

Tendo como pano de fundo o contexto descrito anteriormente, o Quadro 2 apresenta, sumariamente, 0 modelo adotado na 18ª edição dos JEBs.

Quadro 2 - Síntese do modelo dos XVIII Jogos Escolares Brasileiros

\begin{tabular}{|l|}
\hline SíNTESE DO MODELO DOS JEBs DE 1989 \\
\hline 1. Adoção dos princípios do Esporte Educacional \\
\hline 1.1 Participação: estabelecimento de tempo mínimo de participação em modalidades onde a não participação \\
era mais evidente, eliminando a figura do atleta reserva. \\
1.2 Cooperação: eliminação do caráter individualista das disputas, as classificações decorreram da soma dos \\
resultados individuais em favor da equipe. \\
1.3 Coeducação: provas mistas e soma de resultados entre os dois sexos. \\
1.4 Cogestão/corresponsabilidade: formação de Comissão de Alunos para coordenar as participações do \\
segmento estudantil e estabelecer as dinâmicas de grupo que favorecessem a democratização. \\
1.5 Integração: estabelecimento de provas de confraternização entre equipes formadas por alunos de \\
diversos estados. Participação de pessoas com deficiências e de índios. \\
\hline 2. Estrutura organizacional \\
\hline 2.1 Reorientação das comissões de Avaliação (avaliação segundo os princípios de referência estabelecidos), \\
Comunicação Social (criação de sistema de comunicação de acordo com o interesse e expectativas dos \\
estudantes) e Ética (pautado na corresponsabilidade, processo mais democrático entre os participantes em \\
relação aos pareceres sobre situações que feriam os princípios estabelecidos). \\
2.2 Instituição da Comissão de Alunos e da Conferência Brasileira do Esporte na Escola.
\end{tabular}

Continua na próxima página.. 
Continuação do quadro 2 ...

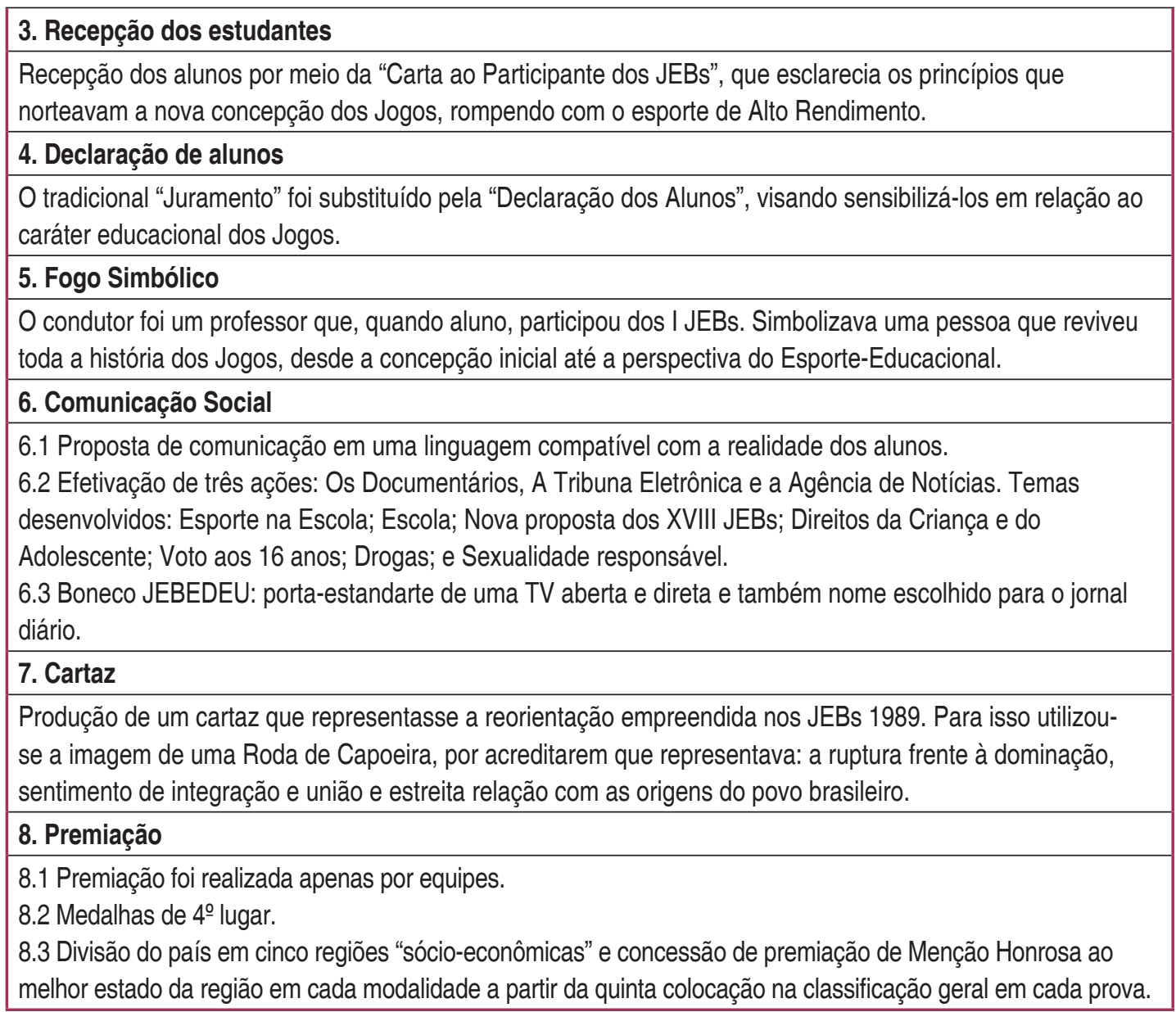

Fonte: Brasil (1989, p. 31-43)

Olhando para o Quadro 2, percebemos características muito peculiares dessa edição. A adoção dos princípios do Esporte Educacional foi a principal estratégia na promoção de mudanças, as quais eram reclamadas não só pelo contexto internacional, mas também pelas discussões em torno do esporte escolar que surgiram na academia brasileira no período. Sobre essa edição, o Agente/ME (2015) destaca que:

[...] foi uma iniciativa de um modelo onde você não deixava nenhum atleta ficar de fora da competição daquele evento, ele era obrigado, nós tínhamos uma súmula, era feito uma súmula, onde 0 atleta era anotado o tempo que ele jogava... ele tinha que jogar no mínimo cinco minutos, [...] porque aquela, 0 cara é ruim não vai jogar, se você trouxe ele no banco ele vai ter que jogar, então tinha um controle da própria súmula, onde todos os atletas tinham que participar no mínimo cinco minutos (AGENTE/ME, 2015, grifo nosso).

Podemos inferir que os Jogos de 1989 tentaram reinventar as competições escolares, trazendo novas perspectivas para o esporte escolar. Muitas simbologias foram suprimidas ou recriadas, destacamos especialmente o "Juramento", a "Tocha Olímpica", a forma de premiação e a forma de participação dos alunos nas competições, esta englobando, entre outras coisas, a participação de todos os inscritos pelo mesmo tempo e a formação de equipes de forma mista (meninos e meninas). De acordo com Pires e Silveira (2007, p. 44) esse modelo de competição gerou desconforto para aqueles que defendiam o esporte-performance e foi construído "não sem a ferrenha oposição e até mesmo o boicote de alguns adeptos e defensores do esporte de 
rendimento na escola [os ortodoxos], que não queriam perder seu espaço [ou suas posições] e glória de vencedores". Sobre esse assunto, de acordo com o relato do Agente/ME (2015, destaque nosso), os JEBs de 1989:

[...] foi um marco,[...] todos os atletas que estavam na competição tinham que participar um período, um tempo dentro do jogo, ou seja, da competição, aquilo foi... não tinha a medalha... a medalha pra equipe como um todo, o cara que tirasse último lugar no atletismo, a equipe dele se ganhasse naquilo, todo mundo ganhava medalha. Então foi uma coisa complicada das pessoas perceberem, era uma atividade legal onde você fazia a participação, quer dizer você não deixar sempre os mesmos jogar, você oportunizar todas as pessoas a participarem do evento foi interessante (AGENTE/ME, 2015, grifo nosso).

A partir do relato acima, percebe-se o que poderíamos denominar de situação de estranhamento, na qual surge um novo arranjo que desestruturava o modelo estabelecido por duas décadas. Como apontam Pires e Silveira (2007), havia nesse contexto um grupo de agentes que defendia o esporte de rendimento na escola, inclusive era esse modelo que imperava nas aulas de Educação Física, ou seja, o do esporte de alto rendimento, o qual foi criticado por autores da área na década de 1980, como Bracht (1986), Medina (1987) e Castellani Filho (1988).

Frente a esse contexto, podemos identificar a existência de imposição de novas práticas em um espaço que já possuía e ainda possui a incorporação e a reprodução de características bastante específicas, como a competição e a performance, mesmo que limitados ao ambiente escolar, ou em termos bourdieusianos, no subcampo da Educação Física Escolar. De acordo com Wacquant (2007 p. 66), o entendimento sobre a interiorização de modos de ser, pensar e agir está diretamente ligado às vivências do mundo social, para o autor "a sociedade tornase depositada nas pessoas sob a forma de disposições duráveis ou capacidades treinadas e propensões estruturadas para pensar, sentir e agir de modos determinados".

Partindo desse entendimento de incorporar o que está externo e manifestar o que está interno, o depoimento do Agente/ME (2015, grifo nosso) apresentado a seguir nos ajuda a constatar algumas nuances do habitus do esporte escolar brasileiro no contexto dos JEBs de 1989:

A discussão foi muito grande, sabe, ou seja, na realidade, as pessoas não entenderam qual era o objetivo daquilo que ficou num problema. $E$ já tinha aquele acirramento, e as pessoas quando viram, e as pessoas que vieram, vieram muito voltadas ainda para um espírito de desporto de rendimento (AGENTE/ ME, 2015, grifo nosso).

Remetendo-nos à ideia de Bourdieu (2003) de que agentes que nascem no campo têm inculcadas em seus corpos as regras do jogo, sabem jogar o jogo, até mesmo sendo capazes de antecipar as jogadas, podemos pressupor a falta de compreensão e de engajamento dos participantes dos JEBs 1989 que se depararam com a imposição de um novo cenário. Ainda em consonância com Bourdieu, as regras do jogo só fazem sentido para quem está inserido nesse contexto, dessa forma, essas novas regras faziam sentido aos idealizadores, mas não aos participantes, pois eram dotadas de preceitos que representavam o campo acadêmico, e não necessariamente o campo político-esportivo, mesmo que em âmbito escolar.

Assim, o "espírito de desporto de rendimento" de professores e alunos participantes dos Jogos, relatado acima pelo Agente/ME, pode ser interpretado, à luz da teoria bourdieusiana, como o sentido do jogo descrito por Bourdieu (1983). As coerções e as exigências do jogo, ainda que não estejam reunidas em um código de regras, "impõem-se àqueles e somente 
àqueles que, por terem o sentido do jogo, isto é, o senso da necessidade imanente do jogo, estão preparados para percebê-las e realizá-las" (BOURDIEU, 2004, p. 82).

O caso em análise demonstra a magnitude do papel exercido pelo sentido e pelo significado nas intenções de práticas sociais dos sujeitos envolvidos. O sentido de jogo do qual falamos anteriormente se constrói, também, pela história do campo, e, nesse caso, a história do esporte escolar mostrava outra direção para o tipo de prática. Podemos pensar ainda na ideia de certa falta de identidade com o modelo do esporte educacional por parte de alguns agentes do esporte escolar brasileiro daquele período, fazendo com que a proposta não tivesse continuidade e não tivesse aderência por parte dos envolvidos.

[...] os professores estavam numa transição e não sabiam o que era aquilo [...], então houve esse não entendimento de algumas pessoas, como podemos dizer, não pegou, o termo exato é esse, não pegou. A proposta não foi pra frente porque não pegou.

Foi só uma vez. É, houve muita crítica, a crítica foi muito grande a respeito disso, né? Hoje talvez alguns estados ainda façam um modelo desse, realizam um modelo desse, então eu acredito que não vingou, eu chamaria que não vingou, não deu certo, mas era uma proposta interessante, porque você obrigava todo mundo a entrar no esquema (AGENTE/ME, 2015, grifo nosso).

Assim como relata o Agente/ME, acreditamos que a proposta era interessante tendo em vista a adoção de princípios distintos aos do alto rendimento, indo ao encontro das discussões sobre o esporte escolar e o esporte como direito social, que estavam em efervescência naquele período, e não pela obrigatoriedade de adequação ao novo padrão. Quando lidamos com sujeitos sociais, "obrigar" uma entrada no esquema - "ele era obrigado"; "era anotado o tempo que ele jogava"; "tinha que jogar no mínimo cinco minutos"; "ele vai ter que jogar"; "tinha um controle" (AGENTE/ME 2015) -, ou ainda impor outro "sentido de jogo", não parece contribuir para alcançar o resultado esperado.

\section{MARCO DE 1989, ALGUMAS CONSIDERAÇÕES FINAIS}

Ao finalizarmos este artigo, que teve como objetivo descrever as características dos JEBs de 1989 e identificar os agentes e as estratégias de ação para o desenvolvimento de um modelo para o esporte escolar, a partir de um olhar da Teoria dos Campos, torna-se possível identificar que os agentes responsáveis pela organização desse evento são oriundos principalmente do campo acadêmico. Por esse motivo, suas ações têm habitus alicerçados em outros campos, que não fundamentalmente o esportivo.

É justo afirmar que nunca antes se viveu na história do esporte brasileiro um momento parecido como esse: impregnado por um contexto internacional de contestação do esporte e somado ao momento de abertura política nacional e às críticas ao esporte de rendimento na área da Educação Física. Os JEBs de 1989 foram fruto dessa nova configuração social, política e cultural. Havia um projeto de mudança para o esporte escolar, embora, na prática, alguns dos agentes envolvidos com o esporte escolar ainda não estivessem familiarizados com o modelo proposto.

É preciso considerar que os jogos escolares nacionais foram consolidados muito antes dos discursos sobre esporte educacional tomarem fôlego na sociedade brasileira. Assim, esses eventos nasceram a partir de um modelo particular de esporte, o do alto rendimento, e a 
tentativa de alinhá-los, e alinhar os sujeitos com ele envolvidos, ao discurso educacional, como a edição realizada em 1989, não teve sucesso esperado nem mesmo em edições posteriores.

Dessa forma, os JEBs de 1989 tornaram-se um "marco" na história do esporte brasileiro, tanto pela inovação proposta (a qual não teve continuidade e o êxito esperado) como por carregar diversas simbologias que retratavam um novo momento político e social brasileiro e uma nova forma de pensar o esporte escolar. Consideramos ainda que esse desdobramento teve como pano de fundo as tensões entre agentes dominantes e dominados do campo acadêmico e do campo político-esportivo marcadas por disputas pela legitimidade do esporte escolar e, consequentemente, dos eventos esportivos escolares. Esperamos que essa leitura e essa análise suscitem outros estudos e posicionamentos na área viabilizando possíveis novas discussões e propostas para futuras ações de políticas públicas do esporte no país.

\section{REFERÊNCIAS}

ARANTES, André; MARTINS, Francisco; SARMENTO, Pedro. Jogos escolares brasileiros: reconstrução histórica. Revista Motricidade, v. 8, n. S2, p. 916-924, 2012.

BARBIERI, César. Educação pelo esporte: algumas considerações para a realização dos Jogos do Esporte Educacional. Movimento, v. 5, n. 11, p. 23-32, 1999.

BORGES, Elisa de Campos; BUONICORE, Augusto César. Memória do esporte educacional brasileiro: breve história dos Jogos Universitários e Escolares. São Paulo: Centro de Estudos e Memória da Juventude, 2007.

BOURDIEU, Pierre. O camponês e seu corpo. Revista de Sociologia Política, n. 26, p. 83-92, jun. 2006.

BOURDIEU, Pierre. Coisas ditas. São Paulo: Brasiliense, 2004.

BOURDIEU, Pierre. Pierre Bourdieu: Sociologia. São Paulo: Ática, 1983.

BOURDIEU, Pierre. Questões de sociologia. Lisboa: Fim de Século, 2003.

BOURDIEU, Pierre. Razões Práticas: Sobre a teoria da ação. 9. ed. São Paulo: Papirus, 1996.

BOURDIEU, Pierre; WACQUANT, Loïc. Una invitación a la sociología reflexiva. Buenos Aires: Siglo XXI, 2005.

BRACHT, Valter. A criança que pratica esporte respeita as regras do jogo... capitalista. Revista Brasileira de Ciências de Esportes, n. 7, v. 2, p. 62-80, 1986.

BRACHT, Valter. Aprendizagem social e educação física. Porto Alegre: Magister, 1992.

BRACHT, Valter. Esporte na escola e esporte de rendimento. Movimento, v. 6, n. 12, p. 14-24, 2000.

BRASIL. Lei no 9.615, de 24 de março de 1998. Institui normas gerais sobre desporto e dá outras providências. 1998. Disponível em: <http://www.planalto.gov.br/ccivil 03/leis/l9615consol. htm >. Acesso em: 6 dez. 2014.

BRASIL. Ministério da Educação. Secretaria de Educação Física e Desportos. Esporte na escola: os XVIII jogos escolares brasileiros como marco reflexivo. Brasília: MEC/SEED, 1989. Disponível em: <http://cev.org.br/arquivo/biblioteca/4019788.pdf >. Acesso em: 9 ago. 2017. 
BUENO, Luciano. Políticas Públicas do Esporte no Brasil: razões para o predomínio do alto rendimento. 2008. 296 f. Tese (Doutorado em Administração Pública e Governo) - Fundação Getulio Vargas, Escola de Administração de Empresas de São Paulo, São Paulo, 2008.

CAVALCANTE, Paulo Henrique de Souza. Sport For All: uma possibilidade de democratização do esporte (?). 2010. 51 f. Trabalho de conclusão de curso (Graduação em Educação Física) Faculdade de Educação Física, Universidade Estadual de Campinas, Campinas, 2010.

CASTELLANI FILHO, Lino. Educação física no Brasil: a história que não se conta. Campinas: Papirus, 1988.

DANTAS JUNIOR, Hamilcar Silveira. Jogos da primavera de Sergipe: tradição, espetáculo e "esportivização da escola" (1964-1995). São Cristóvão: Editora UFS, 2010.

KINZO, Maria D’Alva Gil. A democratização brasileira: um balanço do processo político desde a transição. São Paulo em Perspectiva, v. 15, n. 4, p. 3-12, 2001.

LINHALES, Meily Assbú. A trajetória política do esporte no Brasil: interesses envolvidos, setores excluídos. 1996. 242 f. Dissertação (Mestrado em Ciência Política) - Faculdade de Filosofia e Ciências Humanas, Universidade Federal de Minas Gerais, Belo Horizonte, 1996.

MEDINA, João Paulo Subirá. A educação física cuida do corpo... e "mente": bases para a renovação e transformação da educação física. 7. ed. Campinas: Papirus, 1987.

MENDES. Renato Geraldo. A reformulação do esporte brasileiro. Revista da Fundação de Esporte e Turismo, v. 2, n. 2, p. 34-37, 1990.

PIRES, Giovani de Lorenzi; SILVEIRA, Juliano. Esporte Educacional... Existe? Tarefa e compromisso da educação física com o esporte na escola. In: SILVA, M. R. da (Org.). Esporte, educação estado e sociedade. Chapecó: Argos, 2007. p. 35-53.

TUBINO, Manoel José Gomes. O esporte Educacional como uma dimensão social do fenômeno esportivo no Brasil. In: MEMÓRIAS: Conferência Brasileira de Esporte Educacional. Rio de Janeiro: Editora Central da Universidade Gama Filho, 1996. p. 9-16.

TUBINO, Manoel José Gomes. $\mathbf{5 0 0}$ anos de legislação esportiva brasileira: do Brasil-Colônia ao início do século XXI. Rio de Janeiro: Shape, 2002.

TUBINO, Manoel José Gomes. La educación física y deporte en el mundo contemporáneo. FIEP Bulletin, v. 78, n, 1-2-3, p 38-46, 2008.

TUBINO, Manoel José Gomes. Direito à educação física e ao esporte. Corpus et Scientia, v. 1, n. 1, 2005. Disponível em: <http://apl.unisuam.edu.br/revistas/index.php/corpusetscientia/article/ view/178/146> Acesso em: 9 ago. 2017.

TUBINO, Manoel José Gomes. Estudos brasileiros sobre o esporte: ênfase no esporteeducação. Maringá: Eduem, 2010.

WACQUANT, Loïc. Esclarecer o habitus. Educação \& Linguagem, v. 10, n. 16, p. 63-71, jul./ dez. 2007.

Apoio:

Projeto Inteligência Esportiva, Ministério do Esporte/Universidade Federal do Paraná. 